\title{
Relationship between personality patterns of brain- behavioral Systems, attention bias and pre-attention bias in patients with dependent on methamphetamine
}

\author{
Kiumars Arjmand Ghujur ${ }^{1}$, Ali Eghbali ${ }^{2}$ \\ 1- PhD in psychology, University of Tabriz, Tabriz, Iran (Corresponding Author). ORCID: 0000-0001-5512- \\ $0518 \quad$ Email: Arjomand_k@yahoo.com \\ 2- Assistant professor, Department of Educational Science, Farhangian University, Ardabil, Iran.
}

Received: 25/03/2019

Accepted: 24/06/2019

\begin{abstract}
Introduction: Today, substance abuse is one of the major problems in societies and has become more prevalent among young people.

Aim: The aim of this study was to determine the relationship between personality patterns of brain behavioral systems and attention and pre-attention bias in patients dependent on methamphetamine.

Method: The research was conducted using causal - comparative design. The population from which sample was drawn were all male patients dependent on methamphetamine in TAKAB. 30 people selected based on convenience sampling were compared with control groups. Both groups were homogeneous in terms of demographic variables. Research tools include probe dot task, Gray-Wilson's personality questionnaire (GWPQ), unstructured clinical interview and demographic questionnaire. In order to analyze data in addition to description statistic, the Pearson correlation coefficient and independent t-test were used.

Results: The research findings revealed that the patients who have high score in Behavioral Activation system, especially Drive sub system showed more attention-bias in terms of substance provoking words than other patients. There was no difference among the subjects regarding the pre attention bias.

Conclusion: Considering the fact that the attention bias and brain-behavioral systems play an important role in relapse and re-use of substances, identification and understanding of these factors in treatment seem necessary.

Keywords: Brain- behavioral systems, Attention bias, Pre-attention bias, Methamphetamine
\end{abstract}

How to cite this article : Arjmand Ghujur K, Eghbali A. Relationship between personality patterns of brain- behavioral systems and attention bias and pre-attention bias in patients dependent on methamphetamine .Shenakht Journal of Psychology and Psychiatry. 2019; 6 (3): 46-58 .URLhttp://shenakht.muk.ac.ir/article-1-593-fa.pdf 


\title{
رابطهى الكوهاى شخصيتى مبتنى بر سيستمهاى مغزى - رفتارى با سوكيرى توجه و ويشتوجه در بيماران وابسته به مت آمفتامين
}

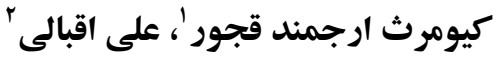

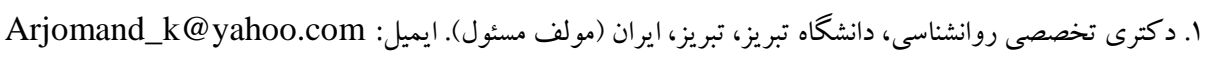 \\ r. استاديار، گروه علوم تربيتى، دانشكاه فرهنكيان، اردبيل، ايران.

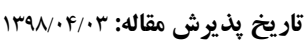

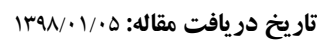

جكيده

مقدمه: امروزه، سوء مصرف مواد به يكى از مشكلات اساسى در جوامع تبديل شده و شيوع آن در بين جوانان بيشتر شده است.

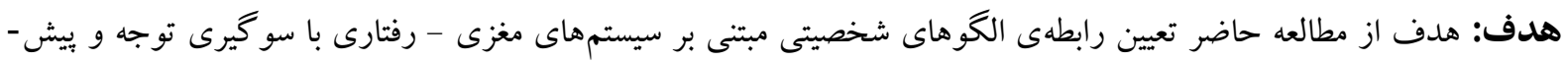
توجه در بيماران وابسته به مت آمفتامين بود. روش: طرح يزوهش از نوع على - مقايسهاى بود. جامعه آمارى شامل تمامى بيماران مرد وابسته به مت آمفتامين شهرستان تكاب

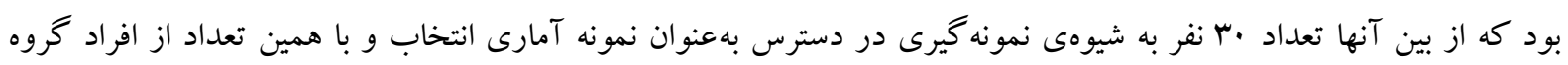

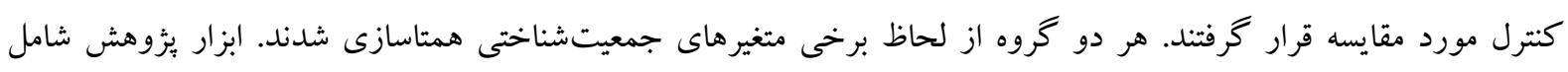

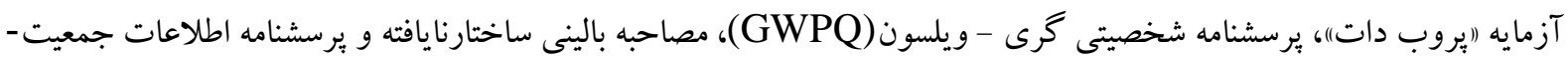

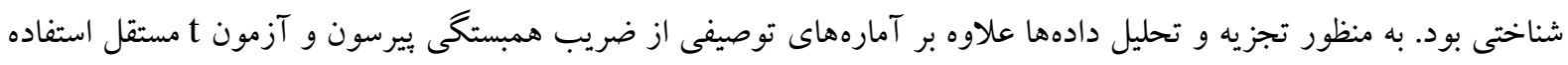
يافتهها: نتايج نشان داد بيمارانى كه نمرات بالايى در سيستم فعالسازى رفتارى بهويزه خرده سيستم سائق و جستجوى لذت بدست

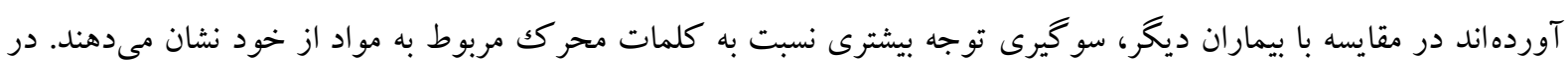
ارتباط با سو گيرى بيش توجه تفاوتى بين افر اد مشاهده نشد.

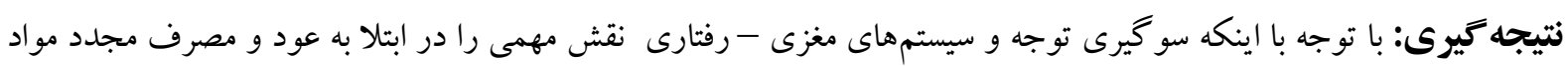

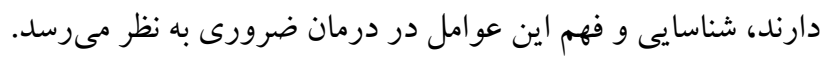

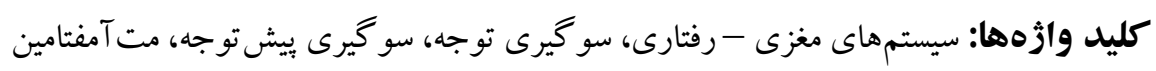


زيستى ارائه نمود كه شامل سه سيستم مغزى - رفتارى

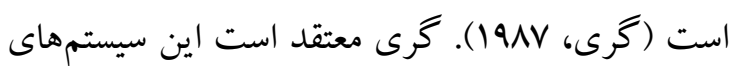
مغزى - رفتارى اساس تفاوتهاى فردى مىباشند و فعاليت هر يكك از آنها به فراخوانى واكنشهاى هيجانى متفاوت، نظير زودانخيختكى، اضطراب و ترس مىانجامد (كرى، (1991، گرى، مئ، (1994). اولين سيستم، سيستم فعالسازى رفتارى^ است كه به محر ككهاى شرطى باداش و فقدان تنبيه بِاسخ مىدهد. فعاليت و افزايش حساسيت اين سيستم موجب فراخوانى هيجانهاى مثبت، رفتار روى آورى و اجتناب

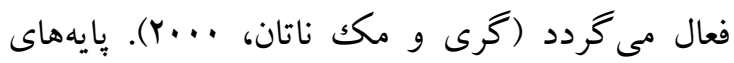
كالبدشناسى عصبى اين سيستم كه از لحاظ ساختارى با

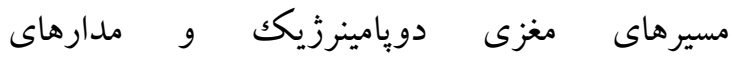

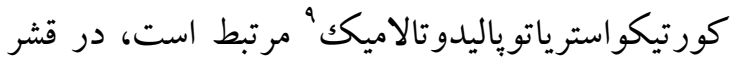
يرهفرونتال، آميگدال و هستههاى قاعدهاى قرار دارد

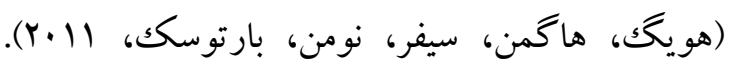

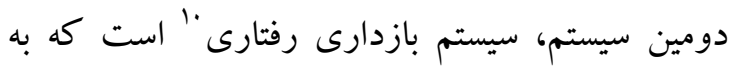

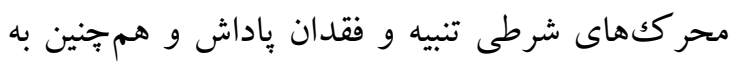
محر ككهاى جديد و محر ككهاى ترس آور ذاتى باسخ

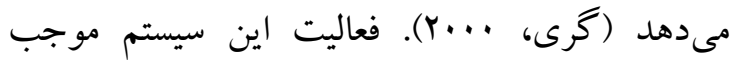
فراخوانى حالت عاطفى اضطراب و بازدارى رفتارى، اجتناب منفعل، خاموشى، افزايش توجه و بريايى مى كردد. پِايههاى كالبدشناسى عصبى اين سيستم كه

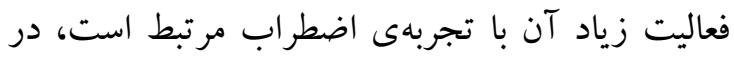

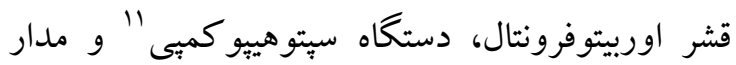

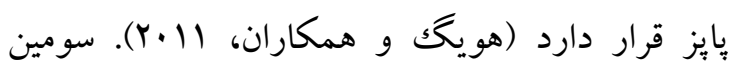

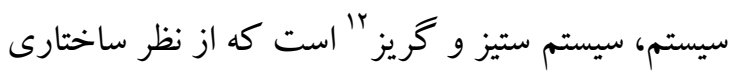
با آميگدال و هييوتالاموس مرتبط و به محر ككهاى
مقلهمه

سوءمصرف مو اد' به ويزّه مصرف مت آمفتامين 'امروزه به يكى از معضلات اصلى در جوامع تبديل شده است. طى يكك دهلى كذشته مصرف مت آمفتامين، به عنوان يكك مشكل قابل توجه در شرق و جنوب شرقى آسيا و شمال آمريكا شناخته شده است. مشاهده شده است كه شيوع استفاده از اين ماده در بعضى از كروههاى اجتماعى نظير جوانان به شكل معنىدارى بيشتر است (بار، ياننكا، مككوان، تورنتون، لانكُك، هونر، لكومتر rا •.Y). مت T مفتامين مادهاى مصنوعى است كه مى توان آن را به صورت خانكى تهيه كرد. مصرف اين ماده، بسيار رايج است. مت آمفتامين باعث افزايش سطح كاته كولآمينها از جمله دوبامين مىشود و اثر عمدهى آن روى .برانخيختخى است. (سادوكى و

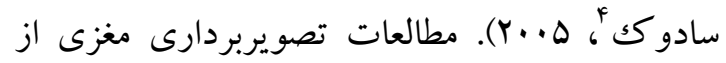
افراد وابسته به مت آمفتامين نشان داده است كه اين افر اد داراى ساختارهاى مغزى نابهنجارى جون تخريب مادهى خاكسترى، قشر ليمبيك و يار اليمبيك، حجم كمتر هيبو كامبٍ، افزايش معنىدار در جسم سفيد، تخريب لوب ميانى بيشانى و بزرگى جسم مخاط مى-

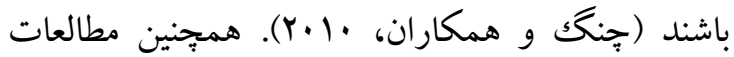
مختلف در طى ساليان اخير نشان مىدهد كه مصرف مواد مخدر و محر كك، كاركرد طبيعى قشر باداشدهى مغز را مورد آسيب قرار داده و مصرف مداوم مواد باعث انحراف در عملكرد سيستم ياداشدهى مغزه مىشود (على مرادى، · ·q ) ).

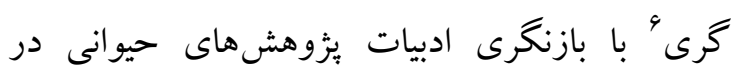
نظريهى حساسيت به تقويت لاز شخصيت يك الكوى

\footnotetext{
1 - substance abuse

2 - methamphetamine

3 - Barr, Panenka, McEwan, Thornton, Lang, Honer, Lecomte

4 - Sadock \& Sadock

5 - Brains Reward System

6 - Gray

7 - Reinforcement Sensitivity Theory
} 
مراحل بردازش اطلاعات هيجانى روى دهد (كلاركى،

.(Ir).

مطالعات مختلف نشان مىدهد كه افراد به طور انتخابى به نشانهايى توجه مى كنند كه با موضوعات برجست مهنى

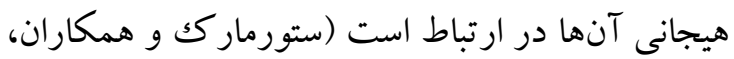

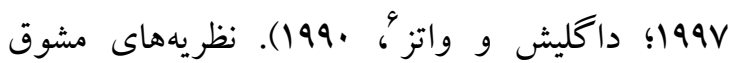

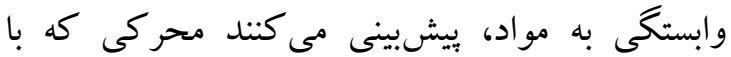

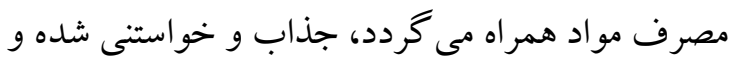
توجه را به خود جلب مىنمايد. به خاطر جنين محركى، براى افراد، برجستخى انخيزشى ايجاد مى رودد. اشتغال ذهنى با اين نشانها مى تواند به عنوان سو گيرى توجه إنه

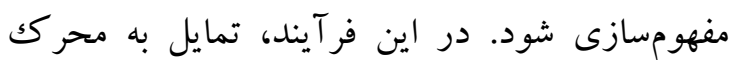

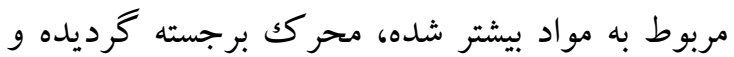

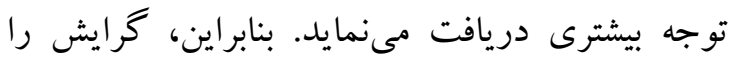
افزايش داده و رفتار را به طرف هدف خاص هدايت

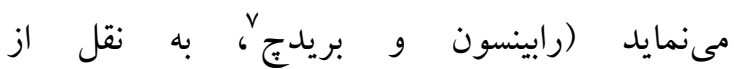

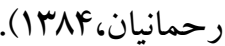

در بررسى بيشينهى يُوهش، مىتوان مطالعهى فرانكن

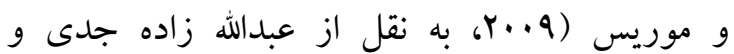

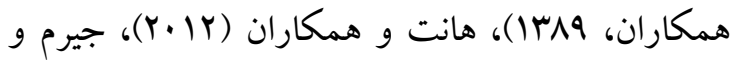

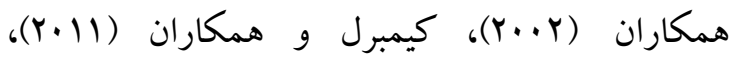

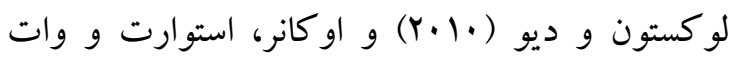
(Y. Y Y (Y) نام برد. در تمامى اين تحقيقات، رابطه مثبت بين اعتياد و خرده مقياس سائق و نيز رابطه مثبت اعتياد با خرده مقياس جستجوى لذت يافت شده است. در اين

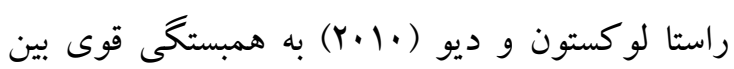
خرده مقياس سائق و خرده مقياس جستجوى لذت با مصرف الكل اشاره كردهاند. برخى مطالعات كه در زمينه ارتباط سيستمهاى فعالساز رفتارى و بازدارنده رفتارى با مشكلات مربوط به سوءصرف الكل انجام

6 - Dulgleish \& Watts

- Robinson \& Berridge
آزاردهنده حساس است. مؤلفههاى رفتارى اين سيستم كه فعاليت زياد آن با يسيكوز گرايى ارتباط دارد، ستيز (يرخاشخر تدافعى) و گريز (فرار سريع از منبع تنبيه)

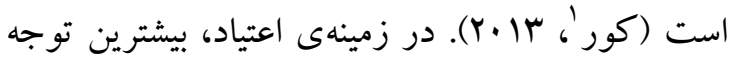
به فعاليت سيستم فعالسازى رفتارى معطوف است و بيشترين يافتها در مورد فعاليت اين سيستم در انسان، از مطالعات مربوط به انتقال دهندهى عصبى دويامين' نشأت مى گيرد. آزادسازى دويامين در مسيرهاى دويامينرزيك مرتبط با سيستم فعالساز رفتارى با جريان يافتن برنامهاى حركتى اين سيستم همراه است

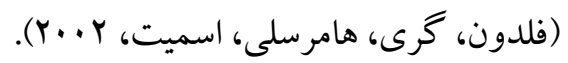
يكى از بحثهاى نظرى عمده در نظريههاى مربوط به هامرسيه

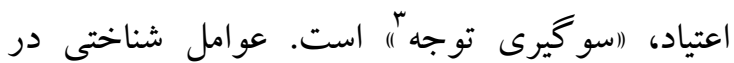
وابستكى به مواد نشان دادهاند كه بردازش اطلاعات

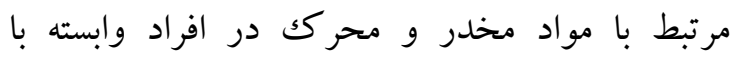

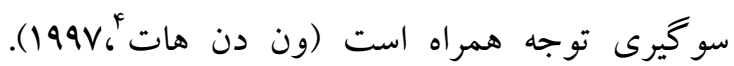
سو گيرى در اينجا براى توصيف هر نوع (برتر گزينى

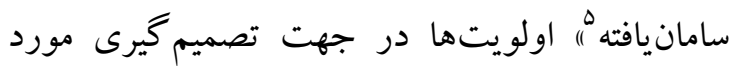
استفاده قرار مى گيرد، به ويزه آن دسته از اولويتها كه دها كزينش يا واگزينش اطلاعات داراى معناى هيجانى را تحت تأثير قرار مىدهند. اين گونه نظريهِيردازىها

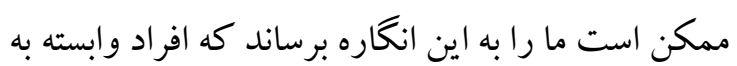
مواد احتمال بيشترى دارد كه اطلاعات مربوط به

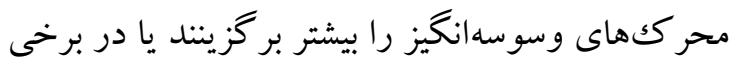

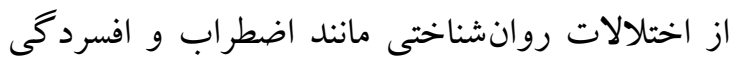
كه افر اد مستعد حالتهاى هيجانى منفى هستند، احتمال بيشترى دارد كه اطلاعات هماهنگك با خلق منفى را بر ززينند. گزينشى از اين دست مى تواند در بسيارى از 
ميزان كرايش به سمت مواد افيونى بيشتر مىشود و مى تواند به عنوان يكك عامل ييشبين در اين زمينه محسوب شود. رحمانيان، ميرجعفى و حسنى (IrAF) به بررسى سو گيرى توجه نسبت به محر ككهاى مربوط به مواد در افراد وابسته به مواد افيونى، مبتلا به عود، تركك كرده و بهنجار קرداختند. نتايج نشان داد افراد وابسته به مواد و مبتلا به عود در مقايسه به افراد تركك

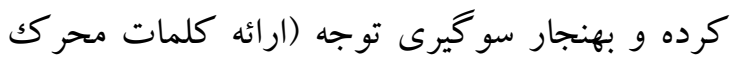
در .ه هزارم ثانيه) بيشترى نشان دادند؛ اما اين تفاوت

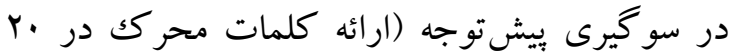
هزارم ثانيه) بين گروهها معنىدار نبود. با توجه با مبانى نظرى بزُوهش و نظر به اينكه تحقيقات داخلى زيادى در اين زمينه و بهويزه در ارتباط با سوءمصرف مواد صورت نخرفته است، مطالعه حاضر با هدف تعيين رابطهى الخوهاى شخصيتى مبتى بر

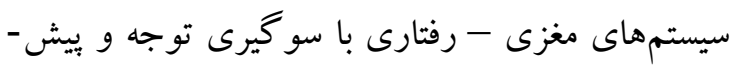
توجه در بيماران وابسته به مت آمفتامين انجام كرفته و فرضيه هاى زير مطرح شده است: 1- بين نمرات بالا در مقياس سيستم فعالسازى رفتارى و سو گيرى توجه نسبت به محر ككهاى مربوط به مواد رابطه وجود دارد. - ابر Y- بين نمرات بالا در مقياس سيستم فعالسازى رفتارى

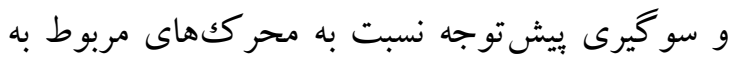
مواد رابطه وجود دارد. ץ- بين نمرات يايين در مقياس سيستم بازدارى رفتارى

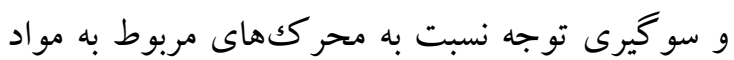
رابطه وجود دارد. F- بين نمرات بايين در مقياس سيستم بازدارى رفتارى

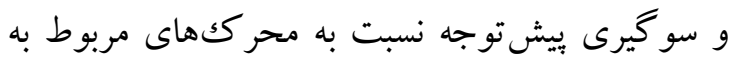
مواد رابطه وجود دارد.
كرفته است، رابطه مثبت معنادار بين حساسيت بالاى سيستم فعالسازى رفتارى و سوءمصرف الكل را نشان دادهاند. رابطه مثبت سوءمرف مواد با فعاليت بالاى

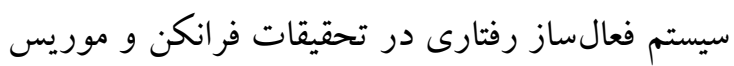

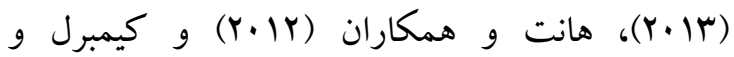
همكاران (Y.11) نشان داده شده است. ييشبينىهاى

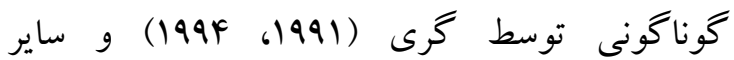

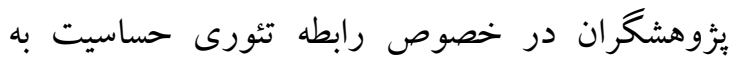
تقويت و آسيبهاى روانى انجام گُرفته است. فاولز

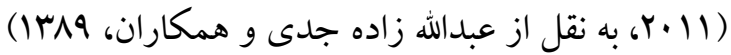
بيان مى كند كه غلبه سيستم فعالسازى رفتارى بر سيستم بازدارنده رفتارى باعث ايجاد خلق تكانشى و و كرايش فرد به سمت تغييرات تقويتى مثبت مواد بدون در نظر گرفتن نتايج منفى متأخره مواد مىشود. شارما،

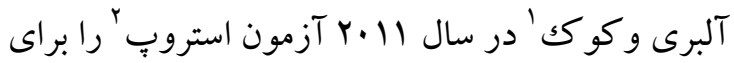
سنجش اين كه آيا بيماران الكلى به طور انتخابى به به بهرب محر ككهاى مربوط به الكل توجه مى كنند و اين كه آيا زمان واكنش با كروه كنترل متفاوت است، به كار بردند. نتايج حاكى از اين بود كه در افراد الكلى زمان

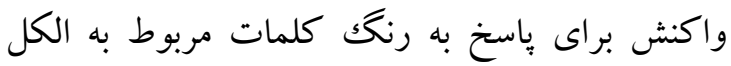
بيشتر از كلمات خنثى بود. از ديخر بُزوهشهاى انجام يذيرفته در اين حيطه،

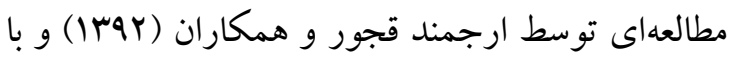
عنو ان بررسى نقش نظامهاى مغزى - رفتارى و مؤلفههاى آن در ييشبينى گر ايش به سمت مواد افيونى درى

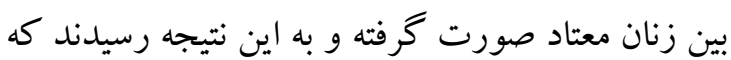
تفاوت معنادارى بين نمرات سيستم فعالساز رفتارى و خرده سيستم جستجوى لذت بين دو گروه از زنان وابسته به مواد افيونى و گروه كنترل وجود دارد؛ به به عبارت ديخر با افزايش نمرات افراد در اين دو عامل ودون 
راست صفحه كليد را فشار دهيد. بعد از آموزش، يكك كار تمرينى ارائه مىشد كه شامل ·ل كوشش بود. در اين ·ل كوشش •ا جفت كلمه يككبار تكرار مىشدند

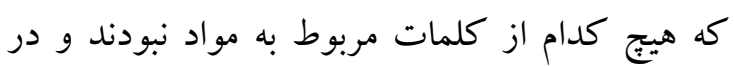
آزمايش اصلى ارائه نمىشد. بعد از اتمام تمرين، آزمودنى •^ كوشش را بدون وقفه دنبال مى كرد. هر تلاش با ظهور نقطه ثابت (+) در وسط صفحه كامييوتر به مدت ا ثانيه شروع مىشد. بس از محو نقطه ثابت، يكك جفت كلمه به مدت يكك دوم ثانيه (...ه هزارم ثانيه) روى صفحه ظاهر مى گرديد. هر دفعه، يكى از كلمات در سمت راست نقطه ثابت و ديخرى در سمت جֶب قرار مى گرفت. وقتى كه كلمات نايديد مى شدند جاى يكى از كلمات محر كك هدف (**) ظاهر مى شد.

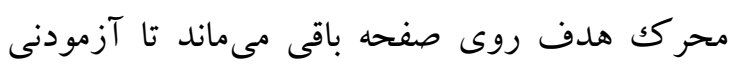

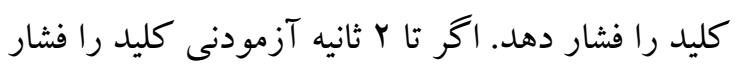
نمىداد، جفت كلمه بعدى ظاهر مىشد. فر آيند اجراى آزمايه براى سنجش سو گيرى بيشتوجه همانند مراحل بالا بود با اين تفاوت كه در اين مرحله، زمان ارائه كلمات به مدت • ب هز ارم ثانيه بود.

ابزار آزمايهى يورب دات؛ آزمايهى ("يروب دات) براى

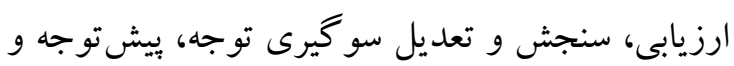
انتقال توجه بينايى توسط روانشناسان شناختى مورد استفاده قرار مى گيرد. در اين تحقيق به استناد از

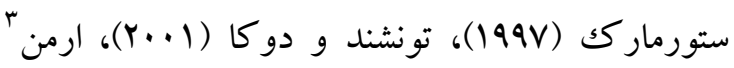

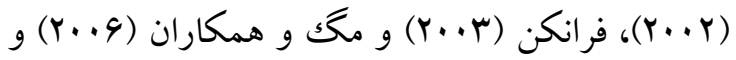
رحمانيان و همكاران (INAF) از آزمايهى بروبدات استفاده شد. در اين برنامه، مكانهاى مخصوصى به وسيله دو مربع مستطيل روى صفحه مانيتور كامبيوتر

${ }_{3}^{2}$ - probe dote task

- Ehrman
طرح يزوهش از نوع على - مقايسهاى است. جامعهى آمارى شامل تمامى بيماران مرد وابسته به مت آمفتامين شهرستان تكاب بود كه در طى سال و9سا به مراكز درمانى و تركك اعتياد اين شهرستان مراجعه كردند. از

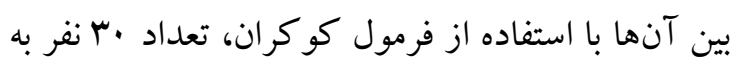
شيوهى نمونه گيرى در دسترس انتخاب و با همين تعداد

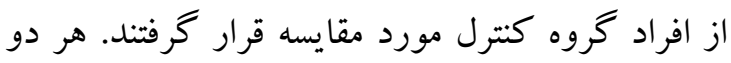
كروه به لحاظ برخى متغيرهاى جمعيت شناختى از جمله سن، جنسيت، سطح تحصيلات، بايخاه اقتصادى -

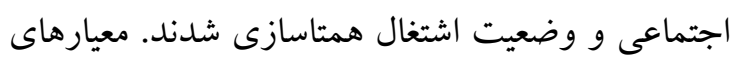
ورود به مطالعه شامل ابتلا و وابستخى به مت آمفتامين

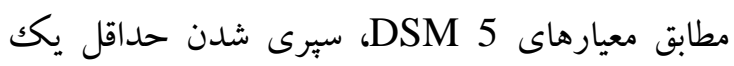
سال از زمان اولين مصرف، داشتن حداقل سطح تحصيلات سيكل و انكيزش و رضايت براى شركت در يثوهش بودند و معيارهاى خروج عبارتاند از: عدم

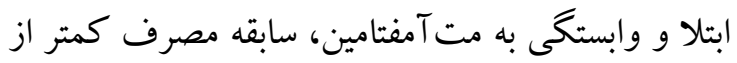
يكك سال، ابتلا به سايكوز و خطر آشكار خود كشى در زمان انجام يُزوهش. انتخاب گرووه كنترل از بين

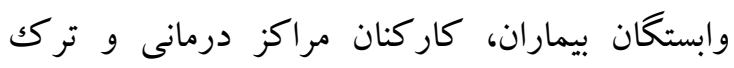
اعتياد اين شهرستان صورت گرفت و هيج كدام از آنها وابسته به مت آمفتامين و يا ساير مواد نبودند. روش اجرا: آزمايهى يروب دات بهوسيله يكك "رايانه دستى" اجرا شد. در طى آزمايش آزمايشخر حضور مداوم و فعال داشت تا از بروز هر گونه ياسخ تصادفى و إنى عدم ياسخ جلو گيرى كند. هر آزمودنى به صورت

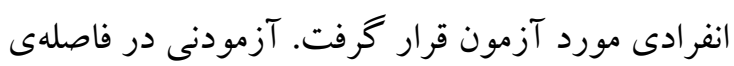
•ه سانتى مترى صفحه مانيتور بر روى صندلى مترلى مىنشست و دستور كار به اين صورت به آزمودنى ارائه مىشد: دو كلمه روى صفحه ظاهر مىشود، بلافاصله بعد از آن، جاى يكى از كلمات يكك علامت ستاره (*) ظاهر مىشود كه بر حسب جاى ستاره كليد جِّ يا يا

1 -note book 
صورت تصادفى صورت مى گيرد (رحمانيان و و

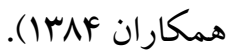

سنجش پِايايى اين ابزار با سى نفر افرادى كه

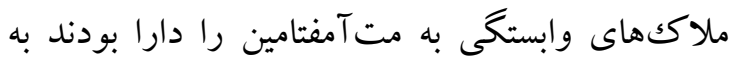

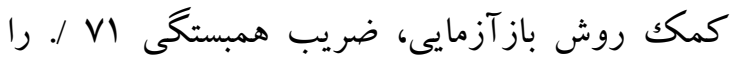
نشان داد. همجِين در يُزوهش رحمانيان و همكاران براى سنجش پِيايى اين ابزار به روش (INAF)

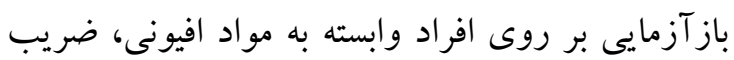

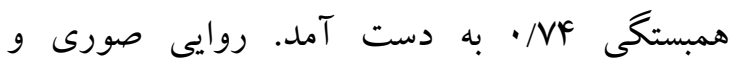
محتوايى آن به كمكك جند تن از اساتيد روانشناسى تائيد شده است.

يرسشنامه شخصيتى ترىى-ويلسون': ويلسون، بارت و

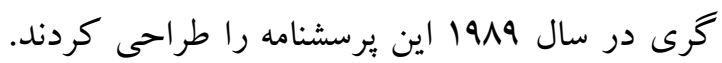
اين يرسشنامه، غلبه و حساسيت سيستمهاى مغزى رفتارى و مؤلفههاى آنها را ارزيابى مى كند و داراى

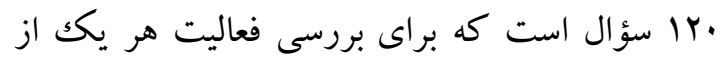
سيستمهاى فعالسازى رفتارى، بازدارى رفتارى و ستيز

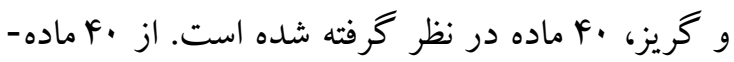
r. r. مربوط به فعاليت سيستم فعالسازى رفتارى ماده به مؤلفهى روى آورد و •r ماده به مؤلفهى

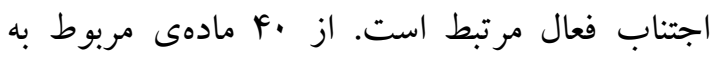
سنجش فعاليت سيستم بازدارى رفتارى، · r ماده مربوط به اجتناب منفعل و · r ماده به مؤلفهى خاموشى اختصاص دارد و از · F مادهى مربوط به

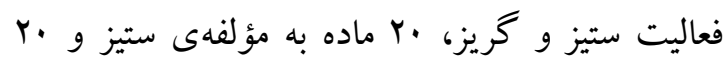
ماده به مؤلفهى گريز اختصاص يافته است. در زمينهى اعتبار اين يرسشنامه، ويلسون، بارت و

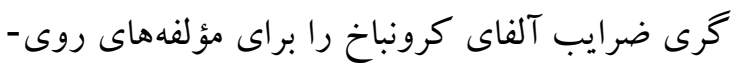

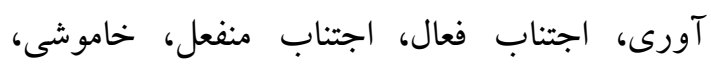

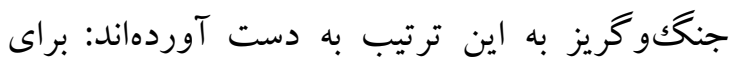
مردان
طراحى شده است، يكى در راست و ديخرى در سمت جִיֶ. يكك نقطه مركزى (علامت+) در وسط صفحه، به عنوان نقطه ثابت، وجود دارد. داخل مستطيلها دو

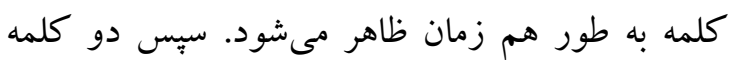

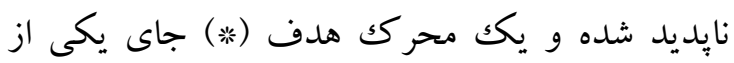

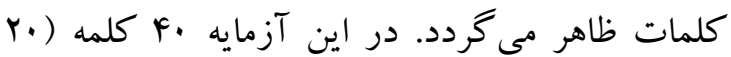
كلمه محر كك مانند شيشه و بايب و • r كلمه خنثى مانند جراغ، ماشين) طراحى شده است كه هر جفت كلمه جهاربار در طول آزمايش تكرار مىشوند. محرك هدف يكك بار جايگزين كلمه مربوط به مواد و يك بار جايخزين كلمه خنثى مى گردد. بنابراين، جهار نوع كوشش مختلف براى هر جفت مرد

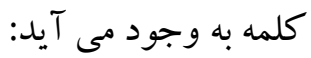
1- كلمه مربوط به مواد و محركك هدف هردو در سمت جِّ، Y- كلمه مربوط به مواد و محر كك هدف هردو در سمت راست، ب- كلمه مربوط به مواد در سمت جِّ و محر كك هدف در سمت راست و Fكلمه مربوط به مواد در سمت راست و محرك هدف در سمت جֶ. كلمات در دو گروه ·F كوششى ارائه مى شوند. در هر كروه، يكك تركيب از هر دو محركى دو بار ارائه مى گردد، يك دفعه محرك هدف ئ جايكزين كلمه

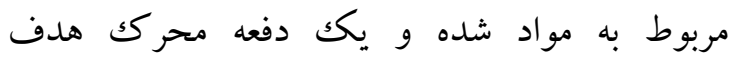
جايگزين كلمه خنثى مى شود. به اين ترتيب، در نيمى

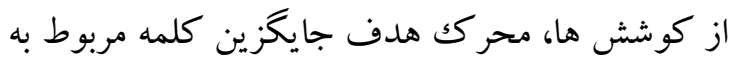

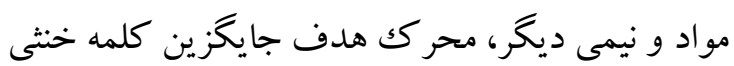
مىشود؛ و به همين ترتيب در نيمى از كوشش ها كلمه

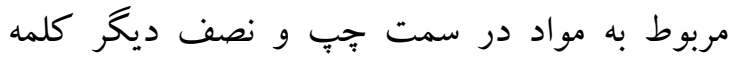
مربوط به مواد در سمت راست ارائه مى شود. ترتيب ارائه گروهها در تمام آزمودنىها ثابت بوده ولى ترتيب ارائه كوشش درون گرووها، براى هر آزمودنى به

\footnotetext{
${ }^{1}$-Gray-Wilson personality Questionnaire $(G W P Q)$
} 
مصرف، وضعيت اشتغال و پايخاه اقتصادى و اجتماعى ت تهيه شده بود. به منظور تجزيه و تحليل دادهها علاوه بر آمارههاى توصيفى، از ضريب همبستكى بير سون، آزمون t مستقل و نرمافزار 1 1 SPSS استفاده شد.

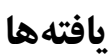
تمامى بيماران شر كت كننده در مطالعه حاضر و گروه كنترل، مرد بودند و در محدوده سنى 1 ا تا FD سال قرار داشتند. از لحاظ وضعيت تأهل در بين بيماران

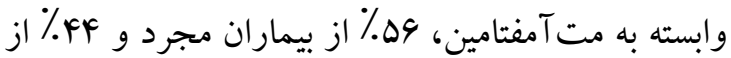

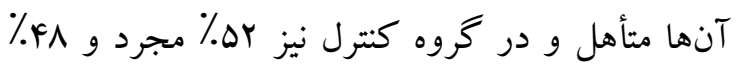
متأهل بودند. ساير دادههاى جمعيتشناختى شركت - مانس

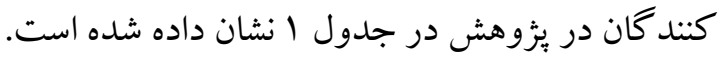

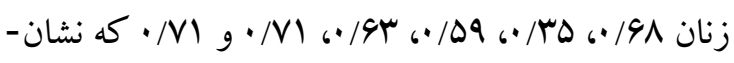
دهندهى ثبات دروانى مناسب آزمون است (علىمرادى

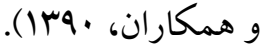
مصاحبهى بالينى ساختار نايافته: مصاحبهى بالينى

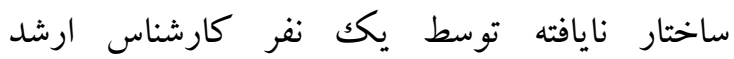
روانشناسى بالينى و به منظور تشخيص سوءمصرف

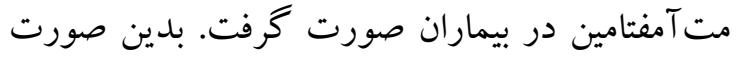
كه اكر تشخيص روانشناس و روان يزشك همخوان بود، فرد به عنوان آزمودنى جهت اجراى ابزار سنجش انتخاب مى گرديد. در غير اين صورت كنار گذاشته مىشد. برسشنامه اطلاعات جمعيت شناختى: اين خرسشنامه جهت جمع آورى اطلاعات جمعيت شناختى آزمودنىها از جمله سن، جنسيت، سطح تحصيلات، مدت و ميزان

جدول ادادههاى جمعيتشناختى بيماران وابسته به مت آمفتامين و كروه كنترل

\begin{tabular}{|c|c|}
\hline ميزان مصرف & مدت مصرف \\
\hline
\end{tabular}

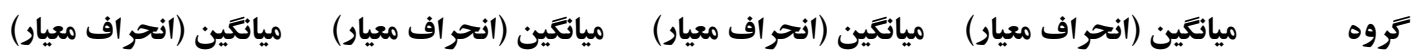

\begin{tabular}{|c|c|c|c|c|}
\hline$(q / \mathrm{IV}) \mathrm{r} / \mathrm{Fq}$ & $(\Delta / \wedge \Delta) F / / F$ & $(G / A Y) \backslash F / F V$ & $(\Delta / Y q) r Y / l \Delta$ & وآبسته بله مت- \\
\hline- & - & (G/YY)ID/rY & $(\Delta / F \Lambda) r Y / G \Lambda$ & كنترل \\
\hline
\end{tabular}

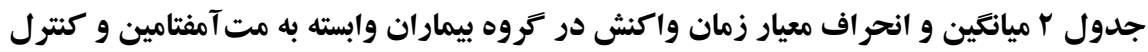

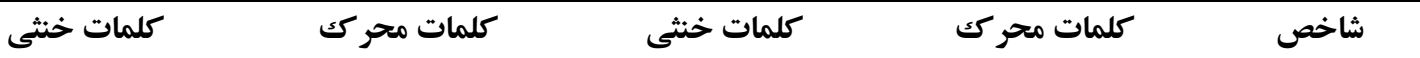

$(r \cdot m s)$

$(r \cdot m s)$

$(\Delta \cdot \cdot \mathrm{ms})$

$(\Delta \cdot \cdot \mathrm{ms})$

كروه ميانكين (انحراف معيار) ميانكين (انحراف معيار) ميانكين (انحراف معيار) ميانكين (انحراف معيار)

\begin{tabular}{|c|c|c|c|c|}
\hline$\left(Q \Lambda / F_{\cdot}\right) \Delta 19 / \Delta V$ & $(91 / F T) \Delta 19 / T V$ & $((1 \Delta / 9 \mathrm{~V}) \Delta \Lambda 9 / V \Delta$ & $(I I Y / A Y) \Delta \Delta F / I V$ & وابسته به مت- \\
\hline$(q T / M r) F \cdot r / l \Delta$ & $(9 r / 9 q) F \cdot r / \Delta$. & $(V V / \cdot q) \& / F / q \Delta$ & $(V q / q 1)$ FID/rr & كنترل \\
\hline
\end{tabular}

موجود از آزمون t مستقل استفاده شد. نتايج در جدول r مشان داده شده است.
به منظور مقايسه دو گروه در سيستمهاى فعالسازى رفتارى، بازدارى رفتارى و ستيز و گريز و تفاوتهاى 


\begin{tabular}{|c|c|c|c|c|c|c|}
\hline $\mathbf{P}$ & $\mathbf{T}$ & df & انحر اف معيار & ميانكين & كروه & شاخصها \\
\hline \multirow[t]{2}{*}{.$\cdots$} & $10 / 1$ & $\Delta \Lambda$ & $r / l$ & $F F / \Lambda$ & وابسته به مت آمفتامين & سيستم فعالسازى رفتارى \\
\hline & & & $F / \Delta$ & $r q / F$ & كنترل ك & \\
\hline \multirow[t]{2}{*}{$\cdot / \cdots$} & $F / 9$ & $\Delta \wedge$ & $r / 9$ & $r \Lambda / F$ & وابسته به مت آمفتامين & سيستم بازدارى رفتارى \\
\hline & & & $r / V$ & $\mathrm{Fr} / \mathrm{q}$ & كنترل & \\
\hline \multirow[t]{2}{*}{$\cdot / \cdots 1$} & $F / V$ & $\Delta \Lambda$ & $F / 9$ & re/o & وابسته به مت آمفتامين & سيستم ستيز و كريز \\
\hline & & & $r / \mu$ & $M F / V$ & كنترل & \\
\hline
\end{tabular}

وابسته به مت آمفتامين بهويزه در خرده سيستم سائق و جستجوى لذت، بيشتر از نمرات گروه كنترل و نمرات بهره سيستم بازدارى رفتارى در گروه كنترل بيشتر از افراد وابسته به مت آمفتامين است. در حالى كه بين دو گرووه از نظر سيستم ستيز و گريز تفاوتى مشاهده نشد.
همانطور كه جدول ץ نشان مىدهد بين بيماران وابسته به مت آمفتامين و گروه كنترل در دو سيستم فعالسازى لهـ رفتارى و سيستم بازدارى رفتارى تفاوت معنىدار

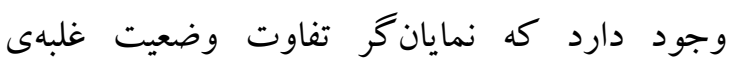
سيستمهاى مغزى - رفتارى آنها مىباشند. نتايج نشان مىدهد كه نمرات سيستم فعالسازى رفتارى در افراد

\begin{tabular}{|c|c|c|c|}
\hline BIS & BAS & شاخص & متغير ملاكك \\
\hline$-\cdot / F Y *$ & $\cdot / \kappa^{\prime}$ * & 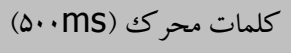 & \multirow{2}{*}{ سوكيرى توجه } \\
\hline.$- / .4$ & $\cdot 1$ & كلمات خنثى (ه.ms) & \\
\hline.$/ \cdot r$ & .1 .9 & كلمات محرك (r.mS) & \multirow[t]{2}{*}{ سو كيرى ييش توجه } \\
\hline.$- / .4$ & $\cdot / \cdot v$ & كلمات خنثى (r.mS) & \\
\hline
\end{tabular}

سازى و بازدارى رفتارى همبستگى نشان نداد؛ بنابراين فرضيه دوم و جهارم يزوهش رد مىشود.

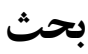

يثزوهش حاضر با هدف تعيين رابطهى الكوهاى شخصيتى مبتى بر سيستمهاى مغزى - رفتارى با

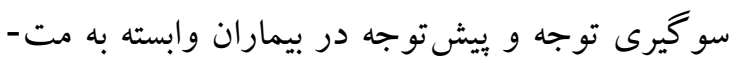
آمفتامين انجام گرفت. يافتهاى يُزوهش نشان داد بين
دادههاى جدول \& نشان مىدهد بين سو گيرى توجه در زمان ارائه كلمات محرك به مدت . .0ه هزارم ثانيه و سيستم فعالسازى رفتارى همبستخى مثبت معنى دار وجود دارد، اما با سيستم بازدارى رفتارى همبستكى منفى معنى دار به دست آمد؛ بنابر اين فرضيه اول و سوم يثوهش تائيد مىشود. از طرف ديخر بين سو گيرى

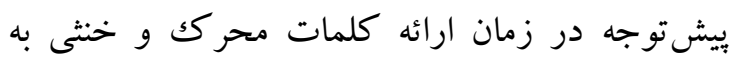
مدت •r هزارم ثانيه و هيجيكك از سيستمهاى فعال- 
مصرف مواد خواهد شد بدون اين كه فرد به عواقب

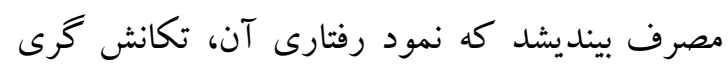
است (عبدى و همكاران، I| (Y)؛ بنابراين حساسيت بالاى سيستم فعالسازى رفتارى در وابستگان مت ماركان آمفتامين در يافتهاى بثزوهش حاضر، تأييد كنندهى

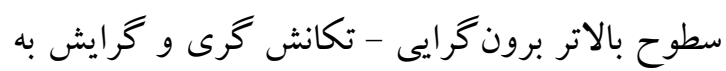

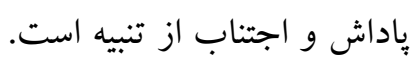
با اين كه اثرات رفتارى و فيزيولوزيكى مت بت آمفتامين مشابه كو كائين و ساير آمفتامينها است، اما آنها

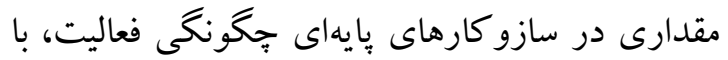
هم متفاوت هستند؛ مثلاً بر خلاف كو كائين، مت بـ

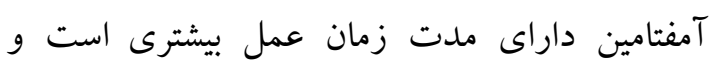
درصد بيشترى از اين دارو بدون تغيير در بدن باقى

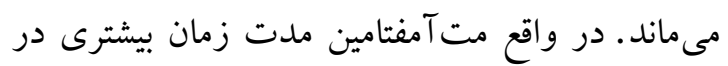

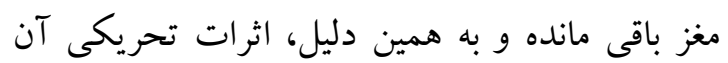

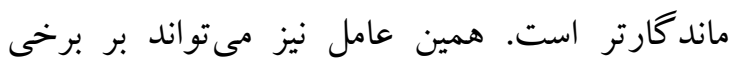
فر آيندهاى شناختى از جمله سو گيرى توجه تأثير داشته

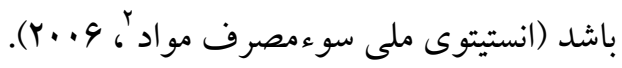

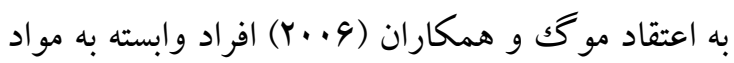
نسبت به محر ككهاى مربوط به مواد رفتارهاى گرايشى بيشترى را بروز مىدهند كه اين رفتارها، با افزايش مدت مصرف با افزايش وسوسه نيز همراه است و بريايه نتايج تحقيقات قبلى مىتوان اذعان داشت كه هر جقدر ميزان وسوسهى مصرف مواد بيشتر باشد، ميزان سو گيرى توجه نسبت به محر ككهاى مربوط به مواد نيز بشتر مى گردد. وجود سو گيرى توجه نسبت به نشانهاى مربوط به مو اد در افراد وابسته به مواد توسط رابينسون و بريدج (Y.V.V) (اسو گيرى توجه)) منعكس كننده فعاليت نظام (احساسيتمشوق" است. به طورى كه در ابتدا سو گيرى نسبت به

\footnotetext{
${ }^{2}$ - National Institute on Drug Abuse (NIDA)
}

نمرات بالا در مقياس سيستم فعالسازى رفتارى و سو گيرى توجه نسبت به محرك كهاى مربوط به مواد رابطهى معنىدارى وجود دارد. همجنين بين نمرات ״ايين در مقياس سيستم بازدارى رفتارى و سو گيرى -

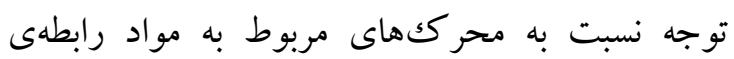

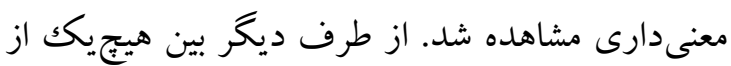
نمرات بالا و بايين در مقياس سيستم فعالسازى رفتارى

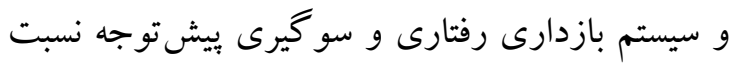
به محر ككهاى مربوط به مواد همبستخى مشاهده نشد. يافته هاى مطالعه حاضر با نتايج برخى تحقيقات قبلى از جمله آزاد فلاح (IMV9)، ارجمند قجور و همكاران

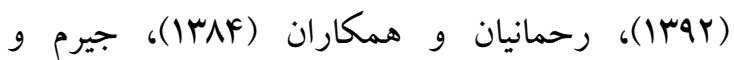

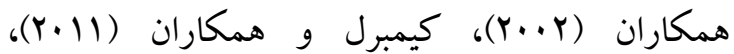

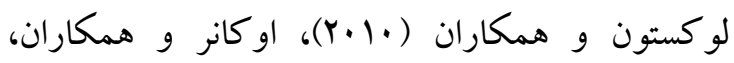

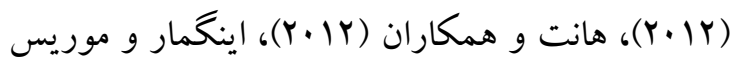

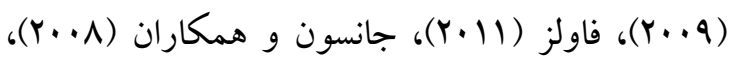
فرانكن و موريس (9. . rا، به نقل از عبدالله زاده جدى و

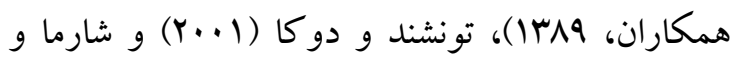

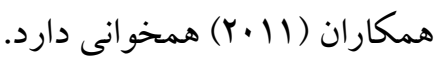

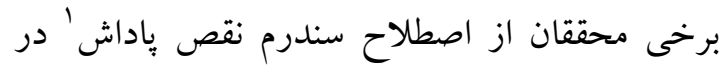

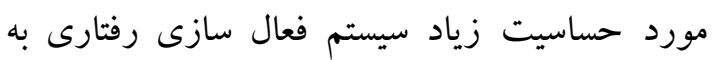
عنوان عامل ممكن در رشد اختلالات مصرف مواد و و رون

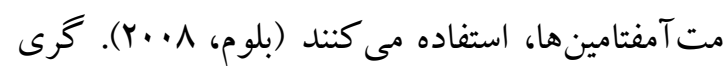
بيان كرد كه سيستم مزولمبيك سوءمصرف كنند كان

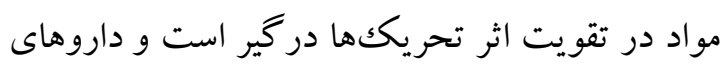

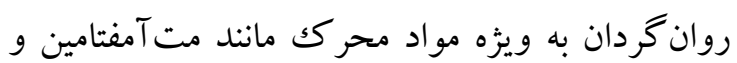
كو كايين بر سيستم دويامينرزيك كه به باسخهاى هيجانى را تنظيم مى كند اثر كذاشته و مسير مزوليمبيك اين سيستم در ايجاد باداش هيجانى مصرف مواد نقش دارد. لذا سيستم فعال سازى رفتارى بالا منجر به تجربهى هيجانهاى مثبت بيشتر در صورت

\footnotetext{
${ }^{1}$ - reward deficiency syndrome
} 
مصرف والكوهاى شخصيتى از جمله نقش سيستم فعال ساز رفتارى را اضافه كرد كه نقش مؤثرى را در سو كيرى توجه ايفاء مى كنند.

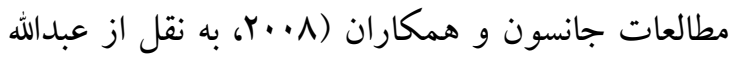
زاده جدى و همكاران، نمرههاى بالاى سيستم فعالساز رفتارى ييشينى كننده سوءمصرف مواد مخدر و محركك از جمله متآمفتامينها و وابستخى به آن است و مطالعه حاضر نيز در راستاى اين تحقيقات گوياى ارتباط معنادار بين نمرههاى بالا در سيستم فعالسازى رفتارى و سو گيرى توجه نسبت به محر ككهاى مربوط به مواد و به دنبال آن

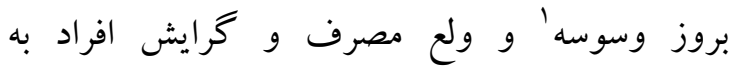
سوءمصرف مواد است.

\section{نتيجه كيرى}

سيستمهاى مغزى- رفتارى به ويزه سيستم فعالسازى رفتارى در گرايش افراد به سوءمصرف مواد نقش بـ يّيشينى كنندهاى ايفا مى كنند. فعاليت بالاى سيستم فعالسازى رفتارى مى تواند عاملى در حساسيت بيشتر

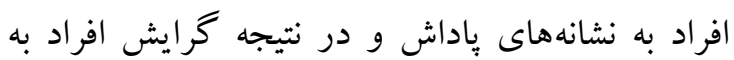
سوءمصرف مواد باشند. عاملى كه سو گيرى توجه رابه همراه خود دارد. در نظر گرفتن اين زيربناهاى زيستى و نورولوزيكى و همجينين فر آيندهاى شناختى دخيل در درد دردئ سوءمرف مت آمفتامين ازجمله سو گيرى توجه، مى تواند گامى در جهت بهبود روند درمان سوءمصرف

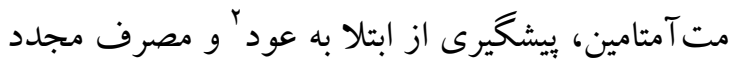
و ويش بينى درمان موفقيت آميز باشد. همجنين مى توان با شناسايى افرادى كه سيستم فعالسازى رفتارى آنان

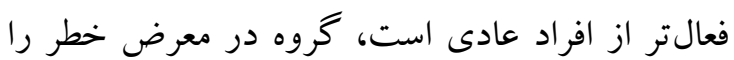

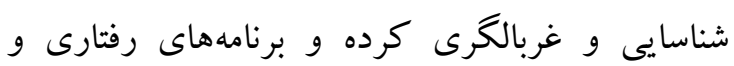

نشانهاى مربوط به مواد توسط اين نظام تعديل

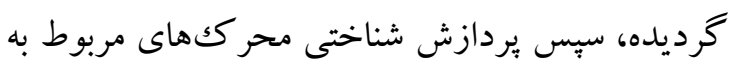
مو اد، باعث برجسته شدن اين نشانه مى گردد. بنابراين، اين نشانها توجه را به خود جلب كرده و رفتارهاى

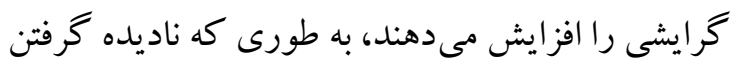
آنها مشكل است. كليهى اين فرآيندها به صورت ناخود آكاه اتفاق مىافتد. يكى از دلايل وجود سو كيرى توجه بيشتر در افراد وابسته به مواد بديده ("تداخل) است. اين بديده كه مبين وجود اختلال در بردازش اطلاعات كنونى فرد است، به دلايل متفاوت ايجاد مىشود؛ مثلاً در بيماران وسواسى و يا افراد وابسته به مواد زمانى كه فرآيند يردازش اطلاعات جديد ماند تعيين رنگك كلمهها صورت مى گيرد، يردازش ييشين يعنى درگيرى ذهنى فرد

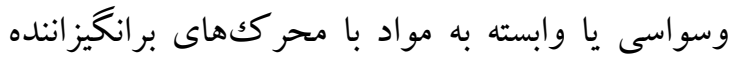
همجنان در جريان است. در نتيجه، يردازش جديد به مثابه يكك عامل مزاحم عمل مى كند و موجب مىشود كه نظام شناختى فرد كندتر پاسخ دهد؛ يعنى به خاطر اينكه افراد داراى وسواس و يا وابسته به مواد داراى سو گيرى خودكار نسبت به محرك كها هستند، توجه آنها در وهلهى نخست به محتواى اين محركها معطوف مىشود و زمانى كه از آنها خو استه مى شود تا با حداكثر سرعت بِاسخ دهند، تداخل ايجاد مىشود و در مقايسه با افراد بهنجار، تعداد محر ككهاى كمترى را تعيين رنگك مى كنند؛ اما از آنجا كه در مورد

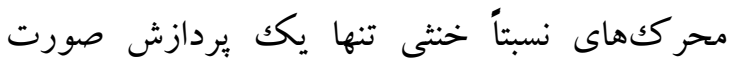
مىيذيرد (يردازش ثانويه) و بديدهى تداخل ايجاد نمىشود و اختلالى هم در سرعت پِاسخدهى آنها

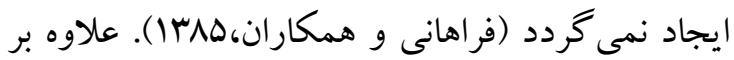
موارد ياد شده مىتوان به عوامل متعددى مانند سطح

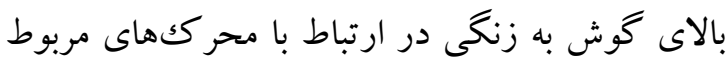

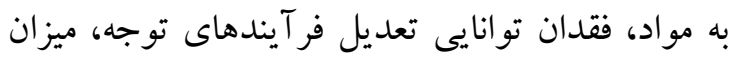


brain differences relevant to stimulant use. Addiction; 102 (1), 33-43.

Azad Falah P. (2000). Biodiversity-psychological foundations for addiction. Joumal of Psychology, 15, 234-246. (In Persian)

Barr A, Panenka W, McEwan W, Thomton A, Lang D, Honer W, Lecomte T. (2013). The need for speed: an update on methamphetamine addiction. $\mathbf{J}$ Psychiatry Neurosci, 31(4), 301-13.

Blum K, Braverman ER, Holder JM, Lubar JF, Monastra VJ, Miller D. (2008). Reward deficiencysyndrome: A biogenetic model for the diagnosis and treatment of impulsive, addictive, and compulsivebehaviors. J Psychoactive Drugs; 32, 1-68.

Chang L, Cloak C, Patterson K, Grob C, Miller EN, Emst T.(2010). Enlarged striatum in abstinent methamphetamine abusers: A possible compensatory response. Biol Psychiatry, 57, 96774.

Corr PJ. (2013). Reinforcement sensitivity theory and personality. Neurosci Biobehav Rev, 28, 317-32.

Dulgleish T, Watts FN. (1990). Biases of attention and memory in disorders of anxiety and depression. Clinical psychology review, 10,589-604.

Ehrman RN, Robbins SJ, Bromwell MA, Lankford ME, Monterosso JRO, Brien CP. (2002). Comparing attentional bias to smoking cues in current smokers, and non-smokers using a dot probe task. Drug and alcohol dependence, 67,185-400.

Feldon J, Gary JA, Hamersley DR, Smith AD. (2002). the neuropsychology of schizophrenia. Behav Brain Sci, 15, $14-9$.

Fowles DC. (2011). Biological variables in psychopathology: a psychobiological perspective. New York: Kluwer Academic/Plenum, 85-141.

Franken IH, Muris P. (2009). BIS/BAS personality characteristics and collegestudents substance use. Per Indiv Differ, 40, 1497-1503.

Graham RB. (1990). Physiological psychology. Saremi A, Rajaie A. (translator). Mashhad: Beh-Nashr, 553-556. (In Persian)

Gray JA, McNaughton N. (2000). the neuropsychology of anxiety: An enquiry into the functions of the septohippocampal system. New York: Oxford University, 53-98.

Gray JA. (1987). Perspectives on anxiety and impulsivity: A commentary. J Res Pers, 21, 493-509.

Gray JA. (1991). Neural systems, emotion and personality. In: Madden JIV. (Editor).

$$
\begin{aligned}
& \text { آموزشى خاصى براى بيشگيرى از گرايش به } \\
& \text { سوءمصرف مواد در اين گروهها ارائه كرد. } \\
& \text { از محدوديتهاى مطالعه حاضر تكك جنسيتى بودن }
\end{aligned}
$$

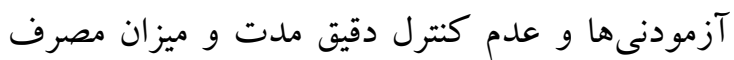

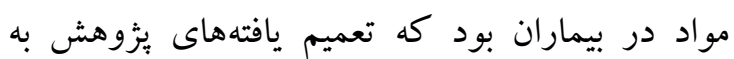

$$
\begin{aligned}
& \text { جوامع آمارى ديخر را با مشكل مواجه مى كند. بيشنهاد } \\
& \text { مىشود در تحقيقات آتى آزمودنىهاى هر دو جنس }
\end{aligned}
$$

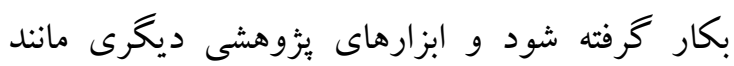

$$
\begin{aligned}
& \text { يروب دات تصويرى و برسشنامه كارور و وايت مورد }
\end{aligned}
$$

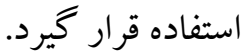

$$
\begin{aligned}
& \text { سياسگزارى } \\
& \text { از مسئولين محترم مر كز تر كك اعتياد شهر ستان تكاب و و } \\
& \text { تمامى بيمارانى كه در مطالعه حاضر شركت داشتند، } \\
& \text { تقدير و تشكر به عمل مى آيد. }
\end{aligned}
$$

\section{References}

Abdi R, Roudsari AB, Aliloo MM. (2011). The sensitivity level of behavioral approach and inhibition systems in substance abusers, smokers and normal subjects. Iranian joumal of psychiatry and clinical psychology, 17(3), 241-7. (In Persian).

Abdullah Zadeh Jedi, A, Hashemi Nosrat Abad, T, Moradi, A, Farzad, V. (2010). The role of brainbehavioral systems in predicting substance abuse, Joumal of Clinical Psychology, 2 (2), 45-37. (In Persian).

Ammanuel DM .(2010). Cognitive Processing of Personally relevant information. Cognition and Emotion, 9(3), 325-40.

Arjmand Ghujur K, pajouhesh, N, Charkhizadeh S. The study of the role of brain-behavioral systems and its components in predicting opiate tendency among addicted women. Congress of Women's Health Promotion, Urmia University of Medical Sciences. 2013 Sep, 25-36, Urmia, Iran (In Persian).

Aron JL, Paulus MP. (2013) Location, location: using functional magnetic resonance imaging to pinpoint Neurobiology of leaming, emotion, and affect. Erlbaum; New York: HillsdaleNJ, 273-306. 
Gray JA. (1994). Framework for taxonomy of psychiatric disorders. In: Cozen MV, Poll V, Sergeant J. (Editors). Emotions: Essays on emotion theory. 12, 29-59.

Green A.I, Salomon MS, BrennerMJ, Rawlins K. (2013) Treatment of schizophrenia and co morbid substance use disorder. Current drug markets. CNS Neurol Disord; 11: 29-39.

Hewig J, Hageman D, Seifert J, Naumann E, Bartussek D.(2011). The relation of cortical activity and BIS/BAS on the trait level. Biol Psychol, 71, 42-53.

Hundt NE, Kimbrel NA, Mitchell JT. (2012). NelsonGrey RO. High BAS but not low BIS, predicts externalizing symptoms in adults. Per Indiv Differ, 44,563-573.

Ingmar HAF, Peter Muris. (2009). BIS/BAS personality characteristics and college students substance use. Per Indiv Differ, 40, 1497-1503.

Johnson SL, Tumer RJ, Iwata N. (2008). BAS/BIS levels and psychiatric disorder/An epidemiological study. J Psychopathol Behav, 25, 25-36.

Jorm AF, Christensen H, Henderson AS, Jacomb PA, Korten AE, Rodgers B.(2002). Using the BIS/BAS scales to measure behavioral inhibition and behavioral activation: Factor structure, validity and norms in a large community sample. Per Indiv Differ, 26, 49-58.

Kimbrel NA, Nelson-Gray RO, Mitchell JT. (2011). Reinforcement sensitivity and maternal style as predictors of psychopathology. Per Indiv Differ, 42, 1139-1149.

Loxton NJ, Dawe S. (2010). How do dysfunctional eating and hazardous drinking women perform on behavioral measures of reward and punishment sensitivity? Per Indiv Differ, 42, 1163- 1172.

Michel SN, Brazell MP. (1999). regionally effects of nicotine. EurJPharmacol, 167(3), 311-22.

Mogg K, Bradley BP, field M, Houwer JD .(2006). Eye movements to smoking - related pictures in smokers: Relationship between attentional biases and implicit and explicit measures in smokers of stimulus valence. Addiction, 98, 825-836.
O'Connor RM, Stewart SH, Watt MC. (2012). Distinguishing BAS risk for university students drinking, smoking and gambling behaviors. Per Indiv Differ, 46, 514-519.

Rahmanian M, Mirjafari A, Hasani J .(2005). Investigating the focus of attention on drug-induced opioid dependents, recurrence, and nomalization. Joumal of Psychology, 36, 428-413. (In Persian)

Robbins TW, Everitt B. (2005). Drug addiction: bad habits add up. Nature, 398, 567-570.

Roberts A. (2012). Psychiatric co morbidity in white and African-American illicit substance abusers: Evidence for etiology. Clin Psychol Rev, 20, 67-77.

Robinson TE, Berridge KC. (2007). The psychology and neurobiology of addiction: an incentive sentization view. addivtion, 95(12), 91-117.

Sadock BJ, Sadock VA .(2005). Kaplan and Sadock's pocket handbook of clinical psychiatry. 4th ed.Arjmand M. (translator). Tehran: Arjmand, 1327. (In Persian)

Sharma D, Albery ID, Cook C. (2011). Selective attentional bias to alcohol related stimuli in problem drinkers and non-problem drinkers. addiction, 96, 285-295.

Stormark KM, field NP, Hugdahl K, Horowitz M. (1997). Selective processing of visual alcohol cues in abstinent alcoholics: An approach- avoidance conflice? addictive behavios , 2(4), 509-519.

Tiffany ST. (2005). Cognitive model of drug urges and drug- use behavior. Role of automatic and nonautomatic processes. psychological Review, 97(2), 147-168.

Townshend JM, Duka T. (2001). Attentional bias associated with alcohol cues: differences between heavy and occasional social drinker. psychopharmacolohy, 157, 67-74.

Van den Hout M, Tenney N, Huygens K, De Jone P. (1997). preconscious processing bias in specific Phobia. behavioral Research Therapy, 35(1) , 2934. 